\title{
Median arcuate ligament syndrome (Dunbar syndrome)
}

\author{
Shams Iqbal, Mahesh Chaudhary \\ Department of Interventional Radiology, Massachusetts General Hospital, Boston, MA, USA \\ Contributions: (I) Conception and design: S Iqbal; (II) Administrative support: S Iqbal; (III) Provision of study materials or patients: S Iqbal; (IV) \\ Collection and assembly of data: None; (V) Data analysis and interpretation: None; (VI) Manuscript writing: Both authors; (VII) Final approval of \\ manuscript: Both authors. \\ Correspondence to: Shams Iqbal, MD, FSIR. Department of Interventional Radiology, Massachusetts General Hospital, Boston, MA, USA. \\ Email: siiqbal@mgh.harvard.edu.
}

\begin{abstract}
Median arcuate ligament syndrome (MALS) is a rare condition which is due to the compression of celiac trunk by low riding of fibrous attachments of median arcuate ligament and diaphragmatic crura. Technically, MALS is a diagnosis of exclusion, consisting of vague symptoms comprising of postprandial epigastric pain, nausea, vomiting and unexplained weight loss. Different imaging modalities like Doppler ultrasound, computed tomography, magnetic resonance imaging and mesenteric angiogram are helpful to demonstrate celiac axis compression. The goal of treatment is decompression of celiac trunk either by open, laparoscopic or robotic method along with adjuvant interventional procedures like percutaneous transluminal angioplasty (PTA) and stenting. Surgical is the mainstay of treatment. This approach is based on open, laparoscopic or robotic release of compressed ligament along with celiac ganglionectomy and celiac artery revascularization. The role of interventional radiology is limited to angioplasty and stenting to open the stenosis rather than addressing the underlying compression of celiac trunk which has resulted in the symptoms. However, both the diagnosis and therapeutic intervention remains challenging. Extensive evaluation of etiology and pathophysiology of MALS and addressing the same through minimally invasive techniques may yield best prognosis in future. In this review article, we discuss briefly about the MALS in terms of etiology, diagnosis and its management including the role of interventional radiology.
\end{abstract}

Keywords: Median arcuate ligament syndrome (MALS); Dunbar syndrome; vascular compression syndrome

Submitted Oct 09, 2020. Accepted for publication Mar 25, 2021.

doi: $10.21037 / \mathrm{cdt}-20-846$

View this article at: http://dx.doi.org/10.21037/cdt-20-846

\section{Introduction}

Median arcuate ligament syndrome (MALS) also called as Dunbar syndrome is a vascular compression syndrome. It is technically known as celiac artery compression syndrome resulting from the compression of celiac axis by median arcuate ligament and diaphragmatic crura. First described anatomically in 1917 by Lipshutz (1), who performed cadaveric dissections and showed the overlapping of celiac artery by the diaphragmatic crura leading to compression. Harjola (2) reported symptomatic relief of postprandial epigastric pain in a 57-year-old man after surgical decompression of the celiac artery from a fibrosis of celiac ganglion. In 1965, Dunbar et al. reported a case series involving surgical management of MALS (3).

The celiac axis generally arises from the abdominal aorta usually between $\mathrm{T} 11$ to $\mathrm{L} 1$, however there is wide variation of its origin (4). The diaphragmatic crura arises form L1L4 where anterior longitudinal ligament meets at anterior and superior aspect of celiac artery. The Median arcuate ligament consists of a band of fibrous tissue connecting anteriorly the diaphragmatic crura surrounding the aortic hiatus. The higher origin of celiac artery or lower insertion of diaphragmatic crura are likely to lead to MALS (Figure 1) (5). Sometimes median arcuate ligament crosses the lower abdominal aorta causing compression (6). Very often compression is increased during expiration due to upward movement of vasculature including the celiac axis. 
A

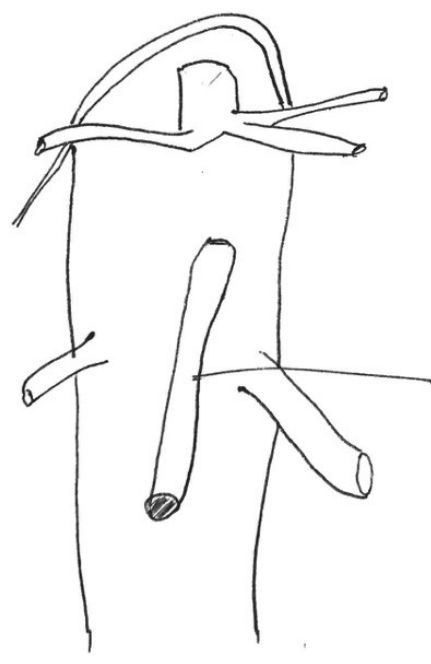

Normal Anatomy
B

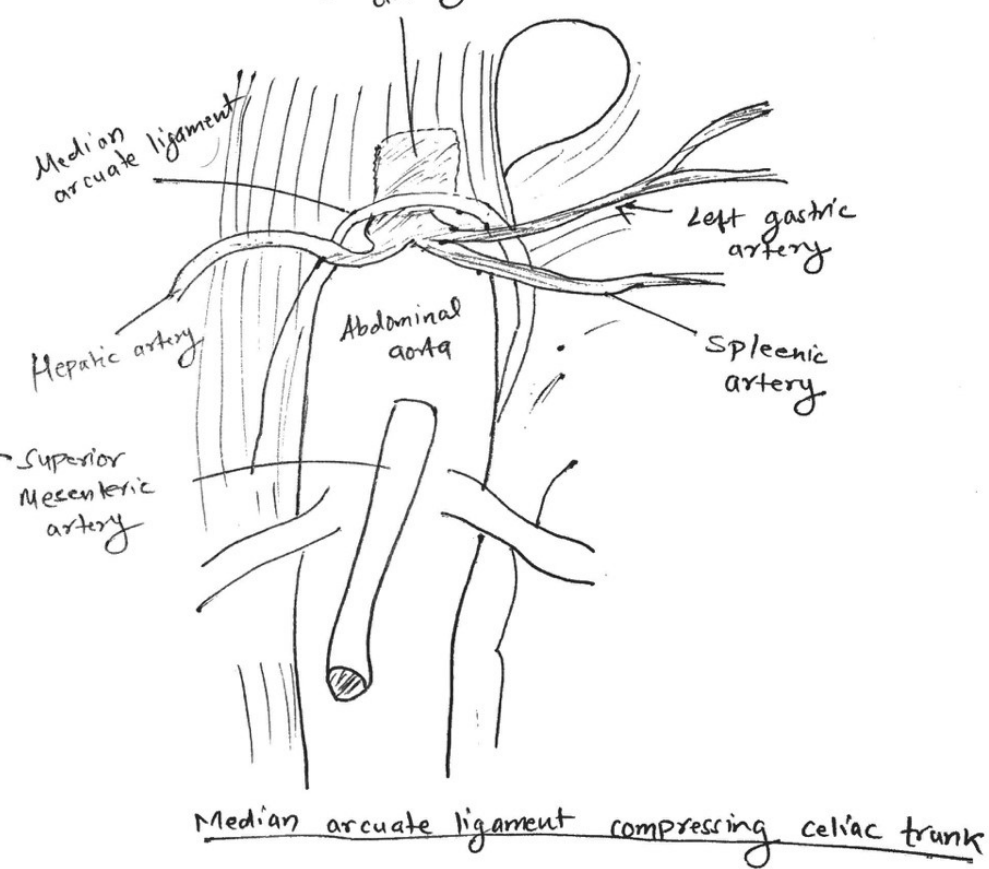

Figure 1 Pictogram comparing relationship of median arcuate ligament and celiac artery. (A) Showing normal anatomical relationship. (B) Shows the descent of median arcuate ligament leading to compressing of the celiac artery in this syndrome.

Compression can be due to thick, fibrous tissue or thin bands at or near the origin of celiac artery (7).

\section{Clinical presentation}

MALS is a rare and is more common in females having thin body habitus in the $3^{\text {rd }}$ to $5^{\text {th }}$ decade of life (8). The syndrome consists of postprandial symptoms including pain, nausea, vomiting, diarrhea and unexplained weight loss $(9,10)$. Cusati et al. (11) in a study consisting of 36 patients with MALS to evaluate the symptoms. This included abdominal pain (94\%), postprandial abdominal pain (80\%), weight loss (50\%), bloating (39\%), nausea and vomiting $(55.6 \%)$, and abdominal pain triggered by exercise $(8 \%)$.

Park et al. (12) in their study of 400 celiac artery angiograms in asymptomatic patients for chemoembolization of hepatic tumors, found that $7.3 \%$ of these patients had significant celiac stenosis, defined as $>50 \%$ stenosis and $>$ a $10-\mathrm{mmHg}$ pressure gradient (12). Derrick et al. reported that celiac artery stenosis presented with post prandial abdominal pain(13).

\section{Diagnosis}

MALS is usually a diagnosis of exclusion. It generally mimics abdominal disorders. Duplex ultrasonography can be a good initial screening tool for celiac artery compression due to its lack of ionizing radiation and contrast need. However, it is operator dependent and needs experienced operator to evaluate and show the changes. In addition, it is limited by body habitus and overlying bowel gas. It can show the post stenotic dilatation and elevated velocities exaggerated during expiration $(14,15)$. Computed tomography angiogram (CTA) helps in the diagnosis allowing three-dimensional visualization of compressed celiac artery. CTA has high resolution and can show changes like post stenotic dilatation (Figure $2 A, 2 B$ ); however, it involves ionizing radiation and needs contrast which can be a limitation in patients with renal dysfunction. Magnetic resonance angiography (MRA) can an alternative modality for those patients who have allergy to intravenous contrast agents. Additionally, MRA does not use ionizing radiation. Conventional angiography is the gold standard to 

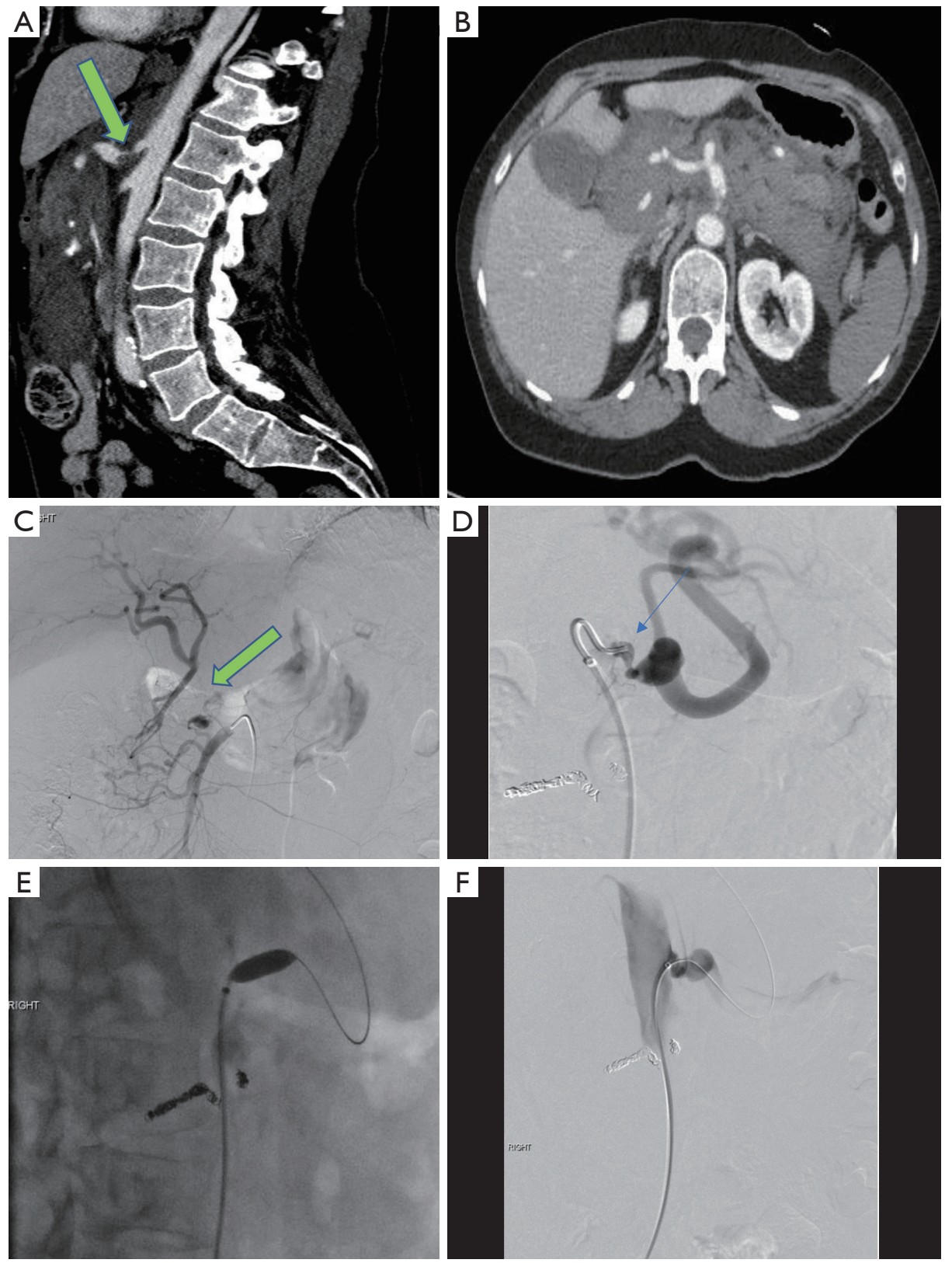

Figure 2 Contrast enhanced CT image of aorta showing focal narrowing at the celiac artery. (A) sagittal image showing the abdomen showing the compression of celiac artery (arrow). (B) Axial image at the level of celiac artery origin showing the stenosis. The patient presented with active bleeding seen around the celiac and hepatic arteries. (C) Celiac angiogram in AP plane showing active extravasation of contrast media (thick arrow) with reconstitution of the hepatic artery by retrograde flow from the superior mesenteric artery (SMA). (D) Post coil embolization of the bleeding, steep right anterior oblique view, the patient was brought on a later date to reevaluate and treat the celiac narrowing (thin arrow). Steep right anterior oblique celiac artery angiogram showing balloon angioplasty image (E) and post angioplasty image $(\mathrm{F})$ with associated improvement in the stenosis. The patient later underwent surgery to complete the treatment.

show dynamic compression. Sometimes lateral mesenteric angiogram can be used for best evaluation of anatomy and dynamic changes (Figure $2 C-2 F$ ). Cephalic movement of the celiac axis during expiration can reveal celiac artery compression and post stenotic dilatation on expiration. Angiography with breathing maneuvers can be very helpful 
for diagnosis. Celiac artery compression can be noted during expiration with associated collaterals developed due to the compression, usually from the superior mesenteric artery (SMA). Angiogram can be also used for the evaluation of the patients who develop symptoms postoperatively (10).

\section{Management}

The treatment of MALS aims at decompression of celiac artery to establish adequate blood flow and pain management by neurolysis. Surgery is the definitive management. Historically, open decompression used to be the first choice, where the surgeon will dissect and separate the diaphragmatic crura from celiac axis. The neuropathic pain of MALS can be addressed with removal or ablation of ganglion and_celiac artery revascularization. With advancement in technology, laparoscopic release of celiac artery has become standard surgical option. The advantages of laparoscopic method are small incision, low risk of complications and improved view during surgery, while disadvantages include incomplete release of celiac artery and potential risk of injury to abdominal aorta (16). The role of intervention radiology is emerging in the treatment of MALS, though its outcomes are not promising. The use of percutaneous transluminal angioplasty (PTA) can be used as an adjuvant therapy prior to surgery. This has some benefit; however, its outcome is not satisfactory when used as a solo treatment. This may be due to the extrinsic compression of celiac artery causing intimal hyperplasia resulting luminal narrowing of artery (17). The present trend is laparoscopic release of arcuate ligament with intraoperative duplex ultrasound. In patients with persistent celiac flow abnormalities noted on duplex ultrasound or postoperative imaging, celiac angioplasty and stenting are logical next step. If this option is not available or does not relieve symptoms, vascular reconstruction should be employed (10).

There is role of PTA in post-surgical recurrence. PTA is useful as an adjuvant in the patients with residual symptoms after surgery with addition of balloon expandable stents(18). Recent trends include robotic assisted release of compression and celiac neurolysis (19).

\section{Conclusions}

MALS is a rare entity and a diagnosis of exclusion. The diagnosis is difficult and needs a high grade of suspicion with supportive imaging findings. The treatment is aimed at relieving the symptoms with open or laparoscopic surgery with PTA and stenting as adjuvant to robotic ligament release and celiac neurolysis. However, further definitive studies are needed to address the pathophysiology, better diagnose and devise minimally invasive treatment for this entity.

\section{Acknowledgments}

Funding: None.

\section{Footnote}

Provenance and Peer Review: This article was commissioned by the Guest Editors (Sanjeeva Kalva and Marcin Kolber) for the series "Compressive Vascular Syndromes" published in Cardiovascular Diagnosis and Therapy. The article has undergone external peer review.

Conflicts of Interest: Both authors have completed the ICMJE uniform disclosure form (available at http://dx.doi. org/10.21037/cdt-20-846). The series "Compressive Vascular Syndromes" was commissioned by the editorial office without any funding or sponsorship. The authors have no other conflicts of interest to declare.

Ethical Statement: The authors are accountable for all aspects of the work in ensuring that questions related to the accuracy or integrity of any part of the work are appropriately investigated and resolved.

Open Access Statement: This is an Open Access article distributed in accordance with the Creative Commons Attribution-NonCommercial-NoDerivs 4.0 International License (CC BY-NC-ND 4.0), which permits the noncommercial replication and distribution of the article with the strict proviso that no changes or edits are made and the original work is properly cited (including links to both the formal publication through the relevant DOI and the license). See: https://creativecommons.org/licenses/by-nc-nd/4.0/.

\section{References}

1. Lipshutz B. A composite study of the coeliac axis artery. Ann Surg 1917;65:159-69.

2. Harjola PT. A rare obstruction of the coeliac artery. report of a case. Ann Chir Gynaecol Fenn1963;52:547-50.

3. Dunbar JD, Molnar W, Beman FF, et al. Compression of the celiac trunk and abdominal angina. Am J Roentgenol 
Radium Ther Nucl Med 1965;95:731-44.

4. Loukas M, Pinyard J, Vaid S, et al. Clinical anatomy of celiac artery compression syndrome: a review. Clin Anat 2007;20:612-7.

5. Horton KM, Talamini MA, Fishman EK. Median arcuate ligament syndrome: evaluation with CT angiography. Radiographics 2005;25:1177-82.

6. Reuter SR, Bernstein EF. The anatomic basis for respiratory variation in median arcuate ligament compression of the celiac artery. Surgery 1973;73:381-5.

7. Brandt LJ, Boley SJ. Celiac axis compression syndrome. A critical review. Am J Dig Dis 1978;23:633-40.

8. Trinidad-Hernandez M, Keith P, Habib I, et al. Reversible gastroparesis: functional documentation of celiac axis compression syndrome and postoperative improvement. Am Surg 2006;72:339-44.

9. Gloviczki P, Duncan AA. Treatment of celiac artery compression syndrome: does it really exist? Perspect Vasc Surg Endovasc Ther 2007;19:259-63.

10. Duffy AJ, Panait L, Eisenberg D, et al. Management of median arcuate ligament syndrome: a new paradigm. Ann Vasc Surg 2009;23:778-84.

11. Cusati DA, Noel AA, Gloviczki P, et al. Median arcuate ligament syndrome: a 20-year experience of surgical treatment. Philadelphia: 60th Annual Meeting of the Society for Vascular Surgery, 2006.

12. Park CM, Chung JW, Kim HB, et al. Celiac axis stenosis: incidence and etiologies in asymptomatic individuals. Korean J Radiol 2001;2:8-13.

13. Derrick JR, Pollard HS, Moore RM. The pattern of arteriosclerotic narrowing of the celiac and superior mesenteric arteries. Ann Surg 1959;149:684-9.

14. Scholbach T. Celiac artery compression syndrome in children, adolescents, and young adults: clinical and color duplex sonographic features in a series of 59 cases. J Ultrasound Med 2006;25:299-305.

15. Skeik N, Cooper LT, Duncan AA, et al. Median arcuate ligament syndrome: a nonvascular, vascular diagnosis. Vasc Endovascular Surg 2011;45:433-7.

16. Takach TJ, Livesay JJ, Reul GJ Jr, et al. Celiac compression syndrome: tailored therapy based on intraoperative findings. J Am Coll Surg 1996;183:606-10. Erratum in: J Am Coll Surg 1997;184:439.

17. Loffeld RJ, Overtoom HA, Rauwerda JA. The celiac axis compression syndrome. Report of 5 cases. Digestion 1995;56:534-7.

18. Columbo JA, Trus T, Nolan B, et al. Contemporary management of median arcuate ligament syndrome provides early symptom improvement. J Vasc Surg 2015;62:151-6.

19. Jaik NP, Stawicki SP, Weger NS, et al. Celiac artery compression syndrome: successful utilization of roboticassisted laparoscopic approach. J Gastrointestin Liver Dis 2007;16:93-6.

Cite this article as: Iqbal S, Chaudhary M. Median arcuate ligament syndrome (Dunbar syndrome). Cardiovasc Diagn Ther 2021;11(5):1172-1176. doi: 10.21037/cdt-20-846 